\title{
The Political Economy of Non Convergence
}

\author{
Fabio Kanczuk*
}

\begin{abstract}
I analyze the joint dynamics of distortionary taxation and economic growth in an environment where taxes are set by self-interested kleptocratic politicians competing for electoral success. The incumbent's incentive to appropriate resources is tempered by a desire to get reelected which would allow him to steal in future periods. Weak electoral control (or high agency costs) is consistent with "distortion-liberalization cycles" - oscillatory movements in economic activity and also with endogenous "political risk", which reduces private investment. Agency costs can therefore account for permanent differences in international growth rates and for the phenomenon of conditional "non-convergence".
\end{abstract}

\section{Resumo}

Eu analiso as dinãmicas conjuntas da tributação distorciva e do crescimento econômico num ambiente em que os impostos são cobrados por políticos kleptocráticos. Os incentivos de um político de se apropriar indevidamente de recursos é moderado por seu interesse de se reeleger, e assim roubar em períodos futuros. Controle eleitoral fraco (ou custos de agência altos) são consistentes com "ciclos de distorção e liberalização" - movimentos oscilatórios na atividade econômica - e com "risco político" endógeno, que reduz o investimento privado. Custos de agência podem, dessa forma, explicar as diferenças permanentes das taxas de crescimento internacionais, e o fenômeno de "não-convergência" condicional.

Key Words: Growth, politics, kleptocracy .

JEL Code:O4,ZO .

*University of São Paulo. I would like to thank Mike Akemann, Laura Alfaro, Gary Hansen, David Levine, Ed Murrugarra, Fede Weinschelbaum, Samuel Pessôa, Maria Cristina Terra, an anonymous referee, and especially Costas Azariadis.

Brazilian Review of Econometrics Rio de Janeiro v.20, nำ, pp.155-188 Nov.2000 


\section{Introduction.}

Observed rates of national economic growth have been very different over sustained periods. The consequences for living standards are enormous. As Lucas (1988) puts it, "Is there some action a government of India could take that would lead the Indian economy to grow like Indonesia's or Egypt's? If so, what, exactly? If not, what is about the nature of India that makes it so? The consequences for human welfare involved in questions like this are simply staggering: Once one starts to think about them, it is hard to think about anything else."

This paper relaxes Lucas' implicit assumption of benevolent government. Viewing politicians as self-interested agents, I change Lucas' question into the following one: What differences in political institutions motivate the Zairean government to take the policy actions that it does instead of those followed by the United States? In order to address this question I analyze a neoclassical growth model in which voters (households) and kleptocratic politicians play the role of principal and agents, in the manner suggested by Tullock (1987), Ferejohn (1986), Grossman (1991) and Benhabib and Rustichini (1996). The incumbents' desire to appropriate resources is moderated by an endogenous electoral constraint. "Agency costs", which describe how much influence households exert on who is in power, determines how much consumption a politician gives up now in order to increase the possibility of stealing in future periods. Changes in power generate cycles at medium frequencies and "political risk", which influences private investment.

The main theoretical results of this paper are that societies with small amounts of electoral control face the worst economic and political outcomes in the long run, e.g., low growth and political instability. Incumbents in these societies act impatiently, distort the economy substantially, and lose power randomly. When electoral control is 
tighter, policymakers act more patiently, and more in accordance with the wishes of voters. The outcome is faster growth and longer incumbencies, that is, endogenous growth and endogenous political stability.

A number of empirical studies (Levine and Renelt (1992), Barro and Sala-i-Martin (1995), Mauro (1995)) report that the difference in income between rich and poor countries has not diminished and even has increased over the last three decades. In addition, these studies list explanatory variables which can robustly account for the observed diversity in growth rates across countries, finding that international trade openness, human and physical capital level and "politics" 1 are the three most relevant factors.

Most of the corresponding theoretical research on the field of growth (Lucas (1988); Azariadis and Drazen (1990)), has focused on studying models of endogenous growth, understanding the mechanics of economic development and analyzing the conditions that are necessary to perpetuate growth. The purpose of that research agenda is to point out the most suitable economic policies that should be undertaken by a benevolent government; including, potentially, trade openness and investment in human capital (education and health). Taking one step further, the political-economy literature on majority voting over tax rates (Meltzer and Richard (1981); Persson and Tabellini (1994); Alesina and Rodrik (1994); Krusell, Quadrini and Rios-Rull (1997)) assumes that the government does exactly what the median voter wants. In societies where income inequality is more pronounced, the median voter prefers redistributive policies that end up harming investment and growth. My approach here is different: I view politicians and political parties as self-interested agents whose objectives may differ a great deal from the median voter's. A desir-

\footnotetext{
${ }^{1}$ Some of the political variables typically used are measures of "freedom of the press", "corruption", "existence of elections", "number of revolutions".
} 
able feature of this line of research is not to specify optimal policies, but rather to describe political institutions that are able to sustain economic development.

The interaction between citizens and policymakers can be thought as a principal-agent problem. In the most developed countries voters exercise tight control over politicians, and consequently policies are closely related to citizen's interests (or, better, the median voter interests); the agent (policymaker) does not deviate much from what the principal (median voter) wants. In less developed countries, however, the control over politicians is very rudimentary, and policymakers are freer to pursue their own interests. How should we describe the politicians' interests in LDC's? Following, among others, Mills (1986), Tullock (1987) and Grossman (1991), I assume politicians are kleptocrats. Notice, however, that this is no different from assuming that the people in government have the same motivations as everyone else. Economists have long assumed that people in the private sector behave as to make themselves as well off as possible. Firms and other asset owners try to obtain the largest possible long-run returns on their assets. Households make employment and consumption decisions so as to make their well-being or utility levels as great as possible. It could hardly be otherwise than that people in government are similarly motivated. The constraints and opportunities are different, but not the motivation.

This simple assumption, which hardly seems disputable, makes much of history intelligible. It implies that governments extract from economies under their jurisdiction as much long run surplus or output as possible and this surplus is used to benefit a very small group ${ }^{2}$. Every political system places some constraints on government's power

\footnotetext{
${ }^{2}$ By government I mean the whole group that benefits from a monopoly or near monopoly of coercive power. I encompasses all the members of the public sector who receive income that would otherwise belong to the rest of nation.
} 
to extract surpluses. Most historical and contemporary political systems impose only mild constraints on this power. Although institutional details vary enormously, the foregoing seems to be a good approximation to what governments have done throughout history in most countries. Due to political or military disruption, Angola's total GDP growth fell from $4.8 \%$ per year in the 60 s to -9.2 in the $70 \mathrm{~s}$; Iran's fell from 11.3 to 2.5 , over the same two periods. How can economic theory account for such striking reversals?

I propose to study a model of endogenous growth in which the economy is populated by $\mathrm{N}$ political parties (kleptocracies) plus a continuum of voters (consumers). The presence of "big" economic agents (policymakers) who don't act competitively, gives rise to a strategic component in economic behavior. The partial randomness of the electoral process leads to a structure classified in the game theory literature as a "Stochastic Dynamic Game". It is in .this framework that I study the relationship between politics and growth. The analysis in divided in two sections.

Section three, "Growth Dynamics", investigates two important phenomena in this economy. The first one is "distortionliberalization cycles", that is, the repeated process of distortion and reform often observed in Latin America. Political parties behave differently in my model because of differences in preferences, survival probabilities, or strategies, i.e., in the degree of "effective impatience", which describes the desire of politicians to "eat now" versus "eating later". These differences lead to regimes of high or moderate taxation and, ultimately, to a choice between anti-growth or pro-growth policies. Thus, at medium frequencies, growth rates display oscillatory movements in response to political changes. Secondly, stochastic changes in policy create "political risk", precisely defined along the lines of Rothschild and Stiglitz (1970). Households respond to this risk by reducing investment and compromising 
economic growth.

Section four, "Electoral Control", is dedicated to understanding in what sense the political environment is different when we compare poor and rich countries. What makes politicians in developed countries behave broadly according to the voters' wishes? In the principal-agent framework that I use the answer relies on endogenous probabilities of reelection, taken as a function of the policies implemented. Voters may reelect politicians who pursue policies more closely related to the electorate's interests, and thus control the politicians' kleptocratic appetites. How well these incentives work depend on "agency costs" (a measure of the depth of information asymmetries, the existence of fair elections, the freedom of media and other cultural expressions, etc.). In countries with higher agency costs (e.g. LDC's) the electorate has less control over politicians; this causes more distortions and political risk and, hence, lowers growth rates.

The analysis pursued here has points in common with papers from different literatures. Chari and Kehoe (1990) apply game theory techniques to study government policies in a macroeconomic general equilibrium model. Rebelo (1991) studied the mechanics in the "AK model" which I use as a foundation. Grossman (1991) assumes rulers are kleptocrats and develops a positive theory of insurrections. More closely related in motivation to this paper are Benhabib and Rustichini (1996) who analyze a game-theoretic model of conflict between social groups. They show how lower growth and even stagnation result when the incentives to domestic accumulation are weakened by redistributive considerations.

\section{Model.}

The economy considered is an extension of a simple endogenous growth model. It is populated not only by a continuum of infinitely 
lived private agents but also by self interested kleptocracies that alternate in the role of government. As is usual in growth models, private agents are assumed to behave competitively: each agent assumes that his decisions can affect neither government policies nor other private agents' decisions. Kleptocracies, in contrast, don't behave as "competitors"; their actions have acknowledged influence on other agents" payoffs.

\subsection{Technology/Timing.}

I borrow the " $A K$ model" framework from Rebelo (1991), where endogenous growth is obtained in a one sector model due to the use of a linear production function. Here $K$ is a composite form of capital, formed by both physical and human capital.

The $A K$ model was chosen for simplicity. Because there is no convergence within this framework, one should remember the correspondence between the growth rate in endogenous growth models and the steady state output level in exogenous growth models (Barro and Sala-I-Martin (1995)). Therefore, different growth rates in the $A K$ model are analogous to non-convergence in a Solow-type growth model.

In each period, actions take place according to the following time line (see Figure 1):

- the available amount of resources for each household $i$ is $y_{t}(i)$ at the start of the period

- households consume a fraction $\theta_{t}(i)$ of these resources, the remainder (savings) constitute the capital level: $k_{t+1}(i)=y_{t}(i)\left[1-\theta_{t}(i)\right]$

- production takes place, leading to an output of $A k_{t+1}(i)$

- households vote

- elections occur (nature plays), and an autocracy $j$ is elected 
- government taxes at a rate $\tau_{j, t+1}$, the new amount of available resources is $y_{t+1}(i)=A k_{t+1}(i)\left[1-\tau_{j, t+1}\right]$

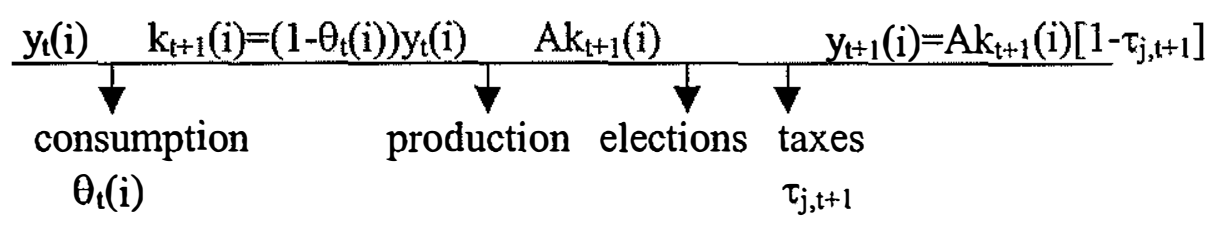

Figure 1: Time line

\subsection{Households (consumers/voters).}

The private sector consists of a continuum of infinitely lived households with mass one, represented by a Lebesgue measure $\lambda$ on the interval $[0,1]$. Households consume and vote. In each period in which autocracy $j$ is in power, an action profile for households is a pair of measurable functions $(\theta, \psi):[0,1] \rightarrow[0,1] \times\left[p_{j, L}, p_{j, H}\right]$ with $0 \leq p_{j, L} \leq p_{j, H} \leq 1$. The first function represents the fraction of the available resources that is allocated to consumption, $c=\theta y$. The second represents "voting", and determines the probability that the incumbent is reelected. I denote the implied action of an individual household $i$ by $(\theta(i), \psi(i))$. The preferences for household $i$ are homothetic

$$
U_{o}(i)=E \sum_{t=0}^{\infty} \beta_{o}^{t} u_{o}\left(c_{t}(i)\right)
$$

where

$$
u\left(c_{t}(i)\right)=\left[c_{t}(i)\right]^{1-\varepsilon_{o}} /\left(1-\varepsilon_{o}\right) \text { if } \varepsilon_{o} \in(0,1)^{3}
$$

${ }^{3} \varepsilon_{o}>1$ would imply that the rate of return-elasticity of savings is negative, i.e., investment rate decreases when rate of return increases. See Hall (1988) for an empirical study of the intertemporal elasticity of substitution. 


$$
\begin{aligned}
& u\left(c_{t}(i)\right)=\ln \left(c_{t}(i)\right) \text { if } \varepsilon_{o}=1 \\
& \beta_{o} \in(0,1) \\
& c_{t}(i)=\theta_{t}(i) y_{t}(i)
\end{aligned}
$$

Its budget constraint is

$$
y_{t+1}(i)=A k_{t+1}(i)\left[1-\tau_{j, t+1}\right]=A y_{t}(i)\left[1-\theta_{t}(i)\right]\left[1-\tau_{j, t+1}\right]
$$

The amount of available resources for a household in period $t+1$ is the fraction from period $t$ resources that was neither consumed by the household nor taxed by the autocracy in power.

\subsection{Autocracies (government).}

In mature democracies political parties are institutions with infinite lives and governments are just representatives of these institutions. Here, to capture rudimentary political systems, rulers are just members of families that hold political power. If a family that is in power (an autocracy) does not get reelected, it is reasonable (and convenient) to assume it can never get elected again.

In each period there are $N$ of these families, "potential" autocracies but just one of them can be in power. Once elected, an autocracy remains in power with some survival probability $p_{t}$; when it loses power, as just argued, it can never regain it. To restore stationarity to the set of potential autocracies, I assume that every time an autocracy loses power (and, thus, dies) another one with the same characteristics is born.

An incumbent autocracy's action is a tax rate $\tau_{j}$, with $\tau_{j} \in[0,1]$ and $j \in\{1,2, \ldots, N\}$. This rate represents the fraction of resources the kleptocracy diverts from the private sector ${ }^{4}$. When not in power,

\footnotetext{
${ }^{4}$ For simplicity, I am abstracting from analysing any other (positive) government's action, e.g., provision of a public good. Rather, I assume there must be an incumbent autocracy in all periods. The analysis can also be seen as a case in which a public good enters separably in the households'utility function.
} 
an autocracy does not have any relevant action, and I set, without loss of generality, $\tau_{j}=0$. At any period, the list of the actions played by all autocracies is $\tau_{t}=\left(\tau_{1, t}, \tau_{2, t}, \ldots, \tau_{N, t}\right)$. Preferences for an autocracy $j$ are also homothetic

$$
U_{j}=E \sum_{t=0}^{\infty} \beta_{j}^{t} u_{j}\left(g_{t}\right)=\sum_{t=0}^{\infty}\left(\beta_{j} p_{t}\right)^{t} u_{j}\left(g_{t}\right)
$$

where

$u_{j}\left(g_{t}\right)=\left[g_{t}\right]^{1-\varepsilon_{j}} /\left(1-\varepsilon_{j}\right)$ if in power and $\varepsilon_{j} \in(0,1)$

$u_{j}\left(g_{t}\right)=\ln \left(g_{t}\right)$ if in power and $\varepsilon_{j}=1$

$u_{j}\left(g_{t}\right)=0$ if not in power

$\beta_{j} \in(0,1)$

$g_{t}=\tau_{j, t} A k_{t}$

$p_{t}=\Psi_{t} \equiv \int \psi_{t}(i) \lambda(d i)$ if in power

$p_{t}=0$ thereafter (after lost power)

Its budget constraint is

$k_{t+1}=A k_{t}\left[1-\tau_{j, t}\right]-c_{t}$

where

$$
\begin{aligned}
k_{t} & =\int k_{t}(i) \lambda(d i) \\
c_{t} & =\int y_{t}(i) \theta_{t}(i) \lambda(d i)=\int A k_{t}(i)\left[1-\tau_{j, t}\right] \theta_{t}(i) \lambda(d i)
\end{aligned}
$$

In the symmetric case, in which all private agents behave alike and have the same amount of resources, we obtain

$$
\begin{aligned}
& \Psi_{t}=\psi_{t}(i) \\
& \Theta_{t} \equiv \int \theta_{t}(i) \lambda(d i)=\theta_{t}(i)
\end{aligned}
$$

This implies the budget constraint

$$
k_{t+1}=A k_{t}\left[1-\tau_{j, t}\right]\left[1-\Theta_{t}\right]
$$

The amount of available resources for the autocracy in power in period $t+1$ is the fraction from period $t$ resources that was neither 
Fabio Kanczuk

taxed by the autocracy in power in period $t$ nor consumed by the households.

\subsection{Elections (Nature).}

In spite of the name I used, we should not restrict elections here to the peaceful political process that occurs in modern democracies. In a world where government often means autocratic power, "voting" might mean just an attempt of households to get rid (or not) of their rulers, possibly with demonstrations, revolutions, etc. Independently of the electoral actions, every period there is a battle for power going on. "Dormant" autocracies are fighting against the incumbent for a chance to exploit society's resources, maybe employing extralegal force. Voting represents the households' effort to participate in the process by which the current government will keep political power or will be replaced by a new autocracy.

In section three, I consider the extreme case where households have absolutely no control over the electoral process. The probabilities of election and reelection of the autocracies are taken as completely exogenous. Hirshleifer (1989) and others study how these probabilities, usually called "Contest Success Functions" can be obtained when the contest is itself explicitly modeled in a general equilibrium setting.

I proceed, in part four, by allowing households to participate on the electoral process. I do so by modeling "voting" as a choice $(\psi)$ that determines the probability of reelection of the incumbent autocracy. Instead of having this probability restricted to be, say, $\psi(i)=p_{j}$, now it can be freely chosen (by the households) within a given set, $\left[p_{j, L}, p_{j, H}\right]$, with $0 \leq p_{j, L} \leq p_{j, H} \leq 1$. The size of the action set, $p_{j, H}-p_{j, L}$, is a measure of how powerful the households are, of how much electoral control they have, and can be interpreted as the magnitude of the "agency costs" of the principal-agent problem. 
In both cases, an election is a stochastic process. Each period that the incumbent is $j$, nature plays, choosing the action $J_{t} \in\{1,2, \ldots, N\}$ - meaning the next autocracy in power - with respective probabilities $\left\{p_{1}, p_{2}, \ldots, p_{N}\right\}$, where $p_{j}=\Psi \equiv \int \psi(i) \lambda(d i)$ (incumbents' reelection probability) and $p_{1}+p_{2}+\ldots+p_{N}=1$. Equivalently, one can say, the electoral process is represented by a probability transition matrix that is chosen by the households, but restricted to be in a set exogenously given.

\subsection{Equilibrium.}

Because households are atomistic, they can only condition their actions on aggregate outcomes. The existence of this informational restrictions lead me to choose, as equilibrium concept, what is called Symmetric Perfect Bayesian Equilibrium (see, for example, Fudenberg and Tirole (1993)). There are, however, too many symmetric perfect bayesian equilibria in this model. I will focus on the subset of these equilibria supported by a class of trigger mechanism, so called revert-to-static strategies. Static Outcomes are those supported by strategies that do not depend on the history at all. Revert-to-static strategies specify reversion to static actions in case of any deviation (See Chari and Kehoe (1990)).

Additionally, I restrict the focus to outcomes that are stationary, i.e., constant over time. In an environment like this, with linear technology and CES preferences, stationary actions imply balanced growth path solutions. All the aggregate variables increase (or decrease) over time at the same rate. On one hand solutions cannot have interesting capital dependence properties. On the other, such a modeling choice represents a necessary step to solve the dynamic programming problem present in each player optimization and thus pursue a more transparent characterization of equilibrium outcomes.

One final remark is needed. All equilibria analysis is conducted 
for the case in which players' lifetime utility is finite and the equilibria actions are in the interior of the action spaces. For finite lifetime utilities it is necessary, when $\varepsilon_{j} \in(0,1), \forall j \in\{0,1, \ldots, N\}$, that the expected growth rate of the economy be less than the utilities intertemporal discount factor: $E\left[(A(1-\Theta)(1-\tau))^{1-e_{j}}\right]<\left(1 / \beta_{j}\right)^{1 /\left(1-\varepsilon_{j}\right)}$; no restriction is necessary when $\varepsilon_{j}=1$. This is equivalent to the usual transversality conditions of growth models. Equilibria actions are interior for a large set of combination of values for the exogenous parameters, no particular restriction has to be made. What is invariantly needed, however, is that autocracies prefer to be in power than to be out of power, when their utility is normalized to zero. This is always true for $\varepsilon_{j} \neq 1$, but has to be ruled out in the logarithmic case, by assuming capital levels are sufficiently high.

\section{Growth Dynamics.}

In this section the political system in the model is simplified in order to focus on growth properties, that is, on the dynamics of the rate of capital accumulation. In particular, I look at the extreme case when voters have absolutely no electoral control. The voting space, $\left[p_{j, L}, p_{j, H}\right]$ when autocracy $\mathrm{j}$ is in power, is restricted to the case $p_{j, L}=p_{j, H}=p_{j}$, i.e., the voting action must be $\psi=p_{j}$. Equivalently, one can say, private agents do not vote strategically.

In what follows, the electoral process is simply a play by nature where autocracy type $j$ is elected with exogenously given probability $p_{j}$, with $p_{1}+p_{2}+\ldots+p_{N}=1$. In addition, this is assumed to be a stationary process in the sense that, in any period, the same autocracy types are available with the same probabilities of election. As mentioned earlier, for this to happen, autocratic families are born to substitute the ones that died.

An economy is thus completely defined by technology and preference parameters together with this probabilities of reelection, 
The Political Economy of Non Convergence

$$
E \equiv\left(A, \beta_{o}, \beta_{1}, \ldots, \beta_{N}, \varepsilon_{o}, \varepsilon_{1}, \ldots, \varepsilon_{N}, p_{1}, \ldots, p_{N}\right)
$$

Outcomes are defined by the relevant actions of players and autocracies,

$$
O \equiv\left(\Theta, \tau_{1}, \ldots, \tau_{N}\right)
$$

\subsection{Characterization of Equilibrium Outcomes.}

As a first step, consider the static equilibrium outcomes, the case where strategies do not depend on past history and not even on the calendar time. More formally, for any history $h_{t}$, an autocracy's static strategy $f_{j}\left(h_{j, t}\right)$ is equal to $\tau_{j}^{s}$ and a household's static strategy $f_{o}\left(i, h_{o, t}(i)\right)$ is equal to $\theta^{s}(i)$.

Proposition 1 (Static equilibrium) The equilibrium outcome of static strategies, $O^{r} \equiv\left(\Theta^{s}, \tau_{1}^{s}, \ldots, \tau_{N}^{s}\right)$, is the solution to the system of equations

$$
\begin{aligned}
& \Theta^{s}=1-\left[\beta_{o} A^{1-\varepsilon_{o}} \sum_{j=1}^{N} p_{j}\left(1-\tau_{j}^{s}\right)^{1-\varepsilon_{o}}\right]^{1 / \varepsilon_{o}} \\
& \tau_{j}^{s}=1-\left[\beta_{j} p_{j} A^{1-\varepsilon_{j}}\left(1-\Theta^{s}\right)^{1-\varepsilon_{j}}\right]^{1 / \varepsilon_{j}}, j \in\{1, \ldots, N\}
\end{aligned}
$$

Proof. (Details in the technical appendix) The equations result directly from the payoff maximization for private agents and autocracies, when each player takes as given other players' actions that are constant over time. For any $j,\left\{\tau_{j, t}\right\}_{t=0}^{\infty}$ maximizes $U_{j}\left(\Theta^{s},\left\{\tau_{j, t}\right\}_{t=0}^{\infty}\right)$, and $\left\{\Theta_{t}\right\}_{t=0}^{\infty}$ maximizes $U_{o}\left(\left\{\Theta_{t}\right\}_{t=0}^{\infty}, \tau_{1}, \ldots, \tau_{N}\right)$.

Example 1 (Logarithmic preferences) When $\varepsilon_{o}=\varepsilon_{j}=1$, the static equilibrium allocations for private agents and autocracies $j$ are respectively, $\Theta^{s}=1-\beta_{o}$ and $\tau_{j}=1-\beta_{j} p_{j}$. The growth rate of the economy in a period autocracy $j$ is elected is $R_{j}=A \beta_{o} \beta_{j} p_{j}$. The growth rate of the economy in any period $t$ is $R_{j}$ with probabit ity $p_{j}$, for $j \in\{1, \ldots N\}$. Notice that the economy grows faster when households have bigger preference discount factor and when the autocracy in power has either bigger discount factor or higher probabil- 
Fabio Kanczuk

ity of reelection.

Now, I use the static equilibrium actions of proposition 1 to help characterize other possible stationary equilibrium outcomes. In particular, I focus on trigger strategies that specify a reversion to the static actions in case of any deviation.

More formally, the "revert-to-static"outcome $O \equiv\left(\Theta^{r}, \tau_{1}^{r}, \ldots, \tau_{N}^{r}\right)$ is supported by the following strategies. For autocracy $j, f_{j}\left(h_{j, t}\right)$ is equal to $\tau_{j}^{r}$ if $h_{j, t}$ elements correspond to $O^{r}$ elements - i.e., if up to period $t$ the aggregate consumption rate was $\Theta^{r}$ and whenever autocracy $j^{\prime}$ was in power, for any $j^{\prime} \in\{1, . ., N\}$, tax ratio was $\tau_{j^{\prime}}^{r}$ - and is equal to $\tau_{j}^{s}$ otherwise. For a household $i, f_{o}\left(i, h_{o, t}(i)\right)$ is equal to $\Theta^{r}$ if $h_{o, t}(i)$ elements correspond to $O^{r}$ elements, and, otherwise, is equal to $\Theta^{s}$.

Proposition 2 (A set of equilibrium outcomes) Revert-to-static equilibrium outcomes,

$$
\begin{aligned}
& O^{r} \equiv\left(\Theta^{r}, \tau_{1}^{r}, \ldots, \tau_{N}^{r}\right), \text { satisfy } \\
& \Theta^{r}=1-\left[\beta_{o} A^{1-\varepsilon_{o}} \sum_{j=1}^{N} p_{j}\left(1-\tau_{j}^{r}\right)^{1-\varepsilon_{o}}\right]^{1 / \varepsilon_{o}} \\
&\left(\tau_{j}^{r}\right)^{1-\varepsilon_{j}} /\left\{1-\beta_{j} p_{j}\left[A\left(1-\tau_{j}^{r}\right)\left(1-\Theta^{r}\right)\right]^{1-\varepsilon_{j}}\right\} \geq \\
&\left\{1-\left[\beta_{j} p_{j}\right]^{1 / \varepsilon_{j}}\left[A\left(1-\Theta^{r}\right)\right]^{\left(1-\varepsilon_{j}\right) / \varepsilon_{j}}\right\}^{-\varepsilon_{j}}, j \in\{1, \ldots, N\}
\end{aligned}
$$

Proof.The first expression indicates that households are playing static best response. The second expression is obtained by making $U_{j}\left(\Theta^{r}, \tau_{j}^{r}\right) \geq U_{j}\left(\Theta^{s}, \tau_{j}^{s}\right)$ for all $j$, is the standard compatibility inequality in trigger strategies equilibria with two remarks. First, solutions do not depend on the stock of capital if all quantities grow at the same rate as in a balanced growth path equilibrium. Hence $\tau$ does not depend on the values for $\Theta$ before $t$. Second, the biggest deviation payoff simply corresponds to the static equilibrium best response.

The LHS's of the inequalities come from a geometric progression with first term $\left(\tau_{j}^{r}\right)^{1-\varepsilon_{j}}$ and ratio $\beta_{j} p_{j}\left[A\left(1-\tau_{j}^{r}\right)\left(1-\Theta^{r}\right)\right]^{1-\varepsilon_{j}}$. The 
RHS's are the value functions coefficients $F_{j}$ obtained in the proof of proposition 1 (see appendix).

This set of expressions guarantee that players do not have incentives to deviate from the equilibrium path. Out of the equilibrium path actions are trivially optimal by proposition 1 , since all players are just playing static best responses.

Proposition 2 indicates that, when facing trigger strategies, autocracies and households behave differently. Autocracies, because of the new incentives created by the "incentive compatibility", have actions that are not necessarily direct functions of other players' actions. Autocracies, one can say, are able to support more favorable outcomes exactly by being vulnerable to punishments. Households, by being anonymous, i.e., for not having their actions observed by other players, cannot be punished for deviating. Hence, households play in proposition 2, as in proposition 1, static best responses.

Even though households' strategies resemble trigger strategies of repeated games, it is important to notice that they behave competitively. Households do not collude to "punish" the government. Rather, after a deviation, households choose the static actions because they forecast that autocracies will also choose the static actions.

The game studied here has a lot in common with the "short run" versus "long run" players games that are extensively studied in the literature (Fudenberg and Levine (1994)). Short run players, by surviving only one period, cannot be punished for deviating, and always play static best response. Long run players, in contrast, just have their actions constrained by some compatibility conditions. In this sense, we can think of autocracies here as being the usual long run players. Households are similar to short run players with a payoff equal to a value function, the sum of the discounted payoffs from now to infinity. 
Proposition 3 (The Worst equilibrium) The static equilibrium is the worst equilibrium for both autocracies and households.

Proof. That autocracies are better off in any revert-to-static equilibrium than in the static equilibrium is trivial from proposition 2 . To prove that households are also better off, the first thing that needs to be shown is that $\tau_{j}^{s}$ is the biggest among all $\tau_{j}^{r}$, for any $j$. Suppose not. If there is a $\tau_{j}^{r}$ bigger than $\tau_{j}^{s}$ then the correspondent $\Theta^{r}$ will be bigger than $\Theta^{s}$ since, from the expression above, $\Theta^{r}$ is increasing in all $\tau_{j}^{r}$. But, in this case, the greatest utility that autocracy $j$ can obtain for a fixed $\Theta$ (that is the utility obtained for the static equilibrium) would be lower than in the original case, when $\Theta=\Theta^{s}$ (This is so because the coefficients $F_{j}$ obtained in the proof of proposition 1 are decreasing in $\Theta$ ). Now, since $\tau_{j}^{r} \leq \tau_{j}^{s}$, we can conclude that for households too the static equilibrium is the worst of all ( $F_{o}$ is decreasing in $\tau_{j}$ )

Interestingly enough, this proposition shows that, in spite of not being vulnerable to punishments, households benefit from the fact that autocracies might support better outcomes for themselves.

\subsection{Effective Impatience.}

An useful way to grasp the influence of the many parameters of the economy in the resulting growth rates is to think about players' actions as their "effective impatience". The word "patience" here captures the idea that players in this economy are facing a intertemporal trade-offs. Policy actions, whether $\theta(i)$ or $\tau$, specify the fraction of available resources that a player decides to "eat" now. The remaining fractions, $1-\theta(i)$ and $1-\tau$, determine the amount of resources that are going to be invested now for the production of future resources, "food" for later periods.

Consider, as a benchmark, example 1 where preferences are logarithmic. Effective impatience for households and autocracies are, 
respectively, $1-\beta_{o}$ and $1-\beta_{j} p_{j}$. Decreases in the discount factor, an indicator of "hunger" now compared to "hunger" later, lead to increases in effective impatience. Effective impatience is also influenced by the probability of remaining in power. A low probability of retaining power in future periods makes an autocracy effectively less patient.

In a more general case, when one attempts to analyze degrees of effective impatience that correspond to static reaction curves (c.f. the expressions given in proposition 1), the results are very ambiguous unless we restrict the curvature of utility functions. This happens because very low $\varepsilon$ leads to very elastic responses to others players actions and to an equilibrium in which the reaction curves cross in "inverted" order. Thus, the following proposition analyzes impatience only in the empirically relevant case of preferences (either of private agents or autocracies) being close enough to logarithmic ${ }^{5}$

Proposition 4 (Effective Impatience in static equilibria). There exist an $\varepsilon_{\min }<1$ such that for either $\varepsilon_{o}>\varepsilon_{\min }$ or $\varepsilon_{j}>\varepsilon_{\min }$ (for all j) the following inequalities hold:

$\partial \Theta^{s} / \partial \beta_{o} \leq 0, \partial \Theta^{s} / \partial A \leq 0, \partial \tau_{j}^{s} / \partial \beta_{j} \leq 0, \partial \tau_{j}^{s} / \partial p_{j} \leq 0$ $\partial \tau_{j}^{s} / \partial A \leq 0$

Proof. From the expressions of proposition 1, we can obtain an expression for $\Theta^{s}$ alone:

$$
\digamma_{o}\left(\Theta^{s}, A, \beta_{o}, \ldots, \beta_{N}, p_{1}, \ldots, p_{N}\right)=0
$$

where

$$
F_{o} \equiv \Theta^{s}-1+\beta_{o} A^{1-\varepsilon_{o}}\left\{\sum_{j=1}^{N} p_{j}^{\left(1-\varepsilon_{o}+\varepsilon_{j}\right) / \varepsilon_{j}} \beta_{j}^{\left(1-\varepsilon_{o}\right) / \varepsilon_{j}}[A(1-\right.
$$
$\left.\left.\left.\Theta^{s}\right)\right]^{\left(1-\varepsilon_{j}\right)\left(1-\varepsilon_{0}\right) / \varepsilon_{j}}\right\}^{1 / \varepsilon_{0}}$

Since the exponent of $\left(1-\Theta^{s}\right)$ in the second term of $F_{0}$ is $\left(1-\varepsilon_{j}\right)\left(1-\varepsilon_{o}\right) / \varepsilon_{j}$, when either $\varepsilon_{o} \rightarrow 1$ or $\varepsilon_{j} \rightarrow 1$ for all $j$,

\footnotetext{
${ }^{5} \varepsilon$ close to one implies that the investment rate is not very elastic to the rate of return.
} 
we obtain $\partial \boldsymbol{F}_{o} / \partial \Theta^{s}=1$. Therefore, in these cases, $\partial \Theta^{s} / \partial x=$ $-\left(\partial \boldsymbol{F}_{o} / \partial x\right) /\left(\partial \boldsymbol{F}_{o} / \partial \Theta^{s}\right) \leq 0$, where $x=A, \beta_{j}$, or $p_{j}$. Now, in similar manner, we define

$$
0=\tau_{j}^{s}-1+\left[\beta_{j} p_{j} A^{1-\varepsilon_{j}}\left(1-\Theta^{s}\right)^{1-\varepsilon_{j}}\right]^{1 / \varepsilon_{j}} \equiv \boldsymbol{F}_{j}
$$

and we can write

$$
{ }_{0,} \partial \tau_{j}^{s} / \partial x=-\left[\left(\partial \digamma_{j} / \partial x\right)+\left(\partial \digamma_{j} / \partial \Theta^{s}\right)\left(\partial \Theta^{s} / \partial x\right)\right] /\left(\partial \digamma_{j} / \partial \tau_{j}^{s}\right) \leq
$$

where $x=A, \beta_{j}$, or $p_{j}$

The direction of these inequalities is very intuitive. If effective impatience represents a player's choice to eat now than later, it depends on how hungry he is now compared to how he will be later, and on the amount of food available now when compared to its amount later. The first factor, hunger, is determined by the utility discount factor $\beta$ : lower $\beta$ means hungry now and hence more effective impatience. The second factor, speed of growth of available resources is determined by the technology parameters $A$. Higher $A$ means better production technology and faster food growth, hence less impatience. Additionally, for an autocracy, a lower probability of reelection means lower chances of eating in the future (or less "available" food) and, hence, more impatience.

\subsection{Distortion-liberalization cycles.}

In all the equilibria of proposition 2 , as in the simple case of example 1 , the composite capital level, $k_{t}$, follows a "stochastic balanced growth path". It grows at a rate $R_{t}$ that is equal to $R_{j}$ with probability $p_{j} . R_{j}$ denotes the growth rate in periods that an autocracy $j$ is elected, and is given by $R_{j}=A(1-\Theta)\left(1-\tau_{j}\right)$.

As I show in figure 2, the time pattern of economic activity can be very complicated. $k_{t}$ follows oscillatory movements with periods 
that are multiples of the electoral process period. At any point in time it may grow faster, slower, or even shrink.

When, in a certain period, autocracy $j$ is elected, it chooses the tax rate $\tau_{j}$ that will directly determine the economic growth rate. As discussed earlier, autocracy $j$ 's effective impatience, $\tau_{j}$, depends on technology and its preference parameters, on its probability of reelection, and on the other players' strategies. If this autocracy is very effective impatient, it chooses a relatively high $\tau_{j}$, distorting a lot the economy now to the detriment of future consumption; as a consequence, the economy grows little or even shrinks. If, instead, this autocracy is not very impatient, it chooses a lower $\tau$, liberalizing the economy in order to enjoy its size in future periods; as a consequence, the growth rate is higher.

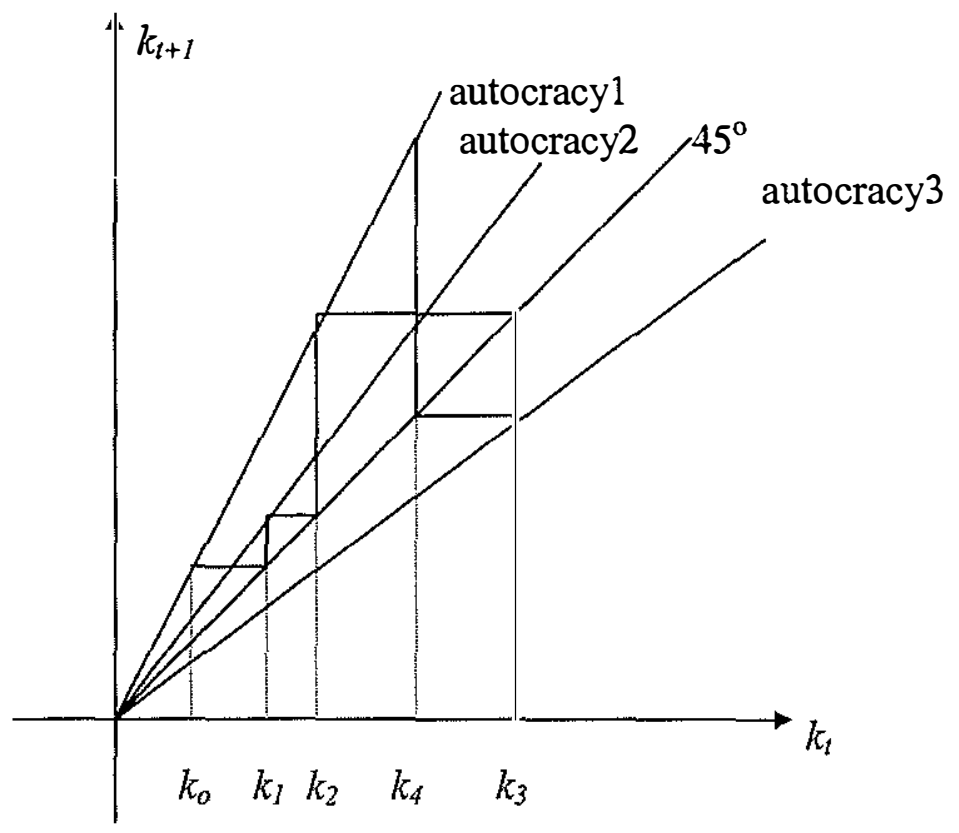

Figure 2: Distortion-Liberalization Cycles 
Differences among autocracies' effective impatience lead to different choices between recessionary or expansionary policies and, ultimately, between regimes of high or moderate taxation. The resulting oscillatory movements in economic activity correspond to what I call the phenomenon of "distortion-liberalization" cycles, a repeated process of distortion and reform.

\subsection{Political Risk.}

Another way of analyzing private agents' actions is to take, as primitives, the equilibrium tax rates $\left\{\tau_{1}, \ldots, \tau_{N}\right\}$. For that I define a Political System as the random variable $\tilde{\tau}$, such that $\tilde{\tau}=\tau_{j}$ with probability $p_{j}$, for $j \in\{1, \ldots, N\}$. Then I approach the model by asking what influence the political system has on the private investment rate $1-\Theta$.

First, a very simple question: What happens if the political system is more (or less) distortionary? If, for a given $j^{\prime}, \tau_{j^{\prime}}$ is changed to a higher (lower) value $\tau_{j^{\prime}}^{*}$, keeping all other $\tau_{j}$ constant? It is straightforward, from the expression for $\Theta^{r}$, that more (less) distortionary political systems lead to lower (higher) private investment rates.

Now, more interestingly, what happens if $\tau_{j}$ are spread out, making the probability distribution of the random variable $\tilde{\tau}$ flatter but still with the same mean? I answer this question, along the lines of Rothchild and Stiglitz (1970,

Definition 1 (Political Risk) A political system $\tilde{\tau}^{\prime}$ is riskier than $\tilde{\tau}$ if $\tilde{\tau}^{\prime}$ and $\tilde{\tau}$ have the same mean and $\tilde{\tau}^{\prime}$ exhibits second-order stochastic dominance over $\tilde{\tau}-$ equivalently, there exist sequences $\tilde{\tau}_{t}$ and $\tilde{\tau}_{t}^{\prime}$, with $\tilde{\tau}_{t} \rightarrow \tilde{\tau}$ and $\tilde{\tau}_{t}^{\prime} \rightarrow \tilde{\tau}^{\prime}$, such that for each $t$, $\tilde{\tau}_{t}^{\prime}$ could have been obtained from $\tilde{\tau}_{t}$ by a finite number of Mean Preserving Spreads (MPS). 
Proposition 5 (Political Risk) Economies with riskier political systems have lower private investment rates and, consequently, slower growth. Households are worse off in economies with riskier political systems.

Proof. (Details in the Appendix). After transforming the households' dynamical problem using Bellman's approach, it reduces to one of the examples contained in the 1971 Rothchild and Stiglitz paper

This definition and proposition generalize the concept of political risk recently addressed in the literature (Alesina, Ozler, Roubini and Swagel (1996) and Cukierman, Edwards and Tabelini (1992)) to the case where political system is any stationary process. Concepts as "polarization" and "political instability" should be considered jointly and not distinctly as it is usual, since they both affect the political system risk.

To better grasp the effect of political risk on growth consider the following example.

Example 2 ( $A$ simple mean-variance case) For an economy with two types of autocracies $(N=2)$, such that $p_{1}=p_{2}=1 / 2$ and $\tau_{1}=\mu+\sigma$ and $\tau_{2}=\mu-\sigma$, the political system has moments $M$ ean $[\tilde{\tau}]=E[\tilde{\tau}]=$ $\mu$ and $\operatorname{Var}[\tilde{\tau}]=\sigma^{2}$. The private investment rate is given by

$$
1-\Theta=(1 / 2)\left(\beta_{o} A^{1-\varepsilon_{o}}\right)^{1 / \varepsilon_{o}}\left[(\mu+\sigma)^{1-\varepsilon_{o}}+(\mu-\sigma)^{1-\varepsilon_{o}}\right]^{1 / \varepsilon_{o}}
$$

We can then easily obtain $\partial(1-\Theta) / \partial \mu \leq 0$ and $\partial(1-\Theta) / \partial \sigma \leq 0$, a political system with more distortion (higher $\mu$ ) or just more risk (higher $\sigma$ ) implies reduction in private savings and in growth rates.

\section{Electoral Control.}

In this section I study how voting helps control politicians' kleptocratic appetites. For that I make several assumptions that help simplify the economy. 
First, in most of the section, I assume there is only one type of autocracy. With this, there are no more oscillatory movements in economic activity. More importantly, since households do not care who the incumbent is, voting is used exclusively to induce politicians into actions that are more to the liking of voters.

Second, I restrict households' preferences to the logarithmic case, which always implies $\Theta=1-\beta_{o}$. Their saving decisions do not depend on other players' actions, or, equivalently, households do not save strategically. As a consequence, the outcome equilibria set of proposition 2 shrinks to a unique element that corresponds to the static equilibrium. This happens because autocracies have no gains from choosing an action different from static one if this choice does not cause changes in households' savings.

Now an economy can be defined by $E \equiv\left(A, \beta_{o}, \beta, \varepsilon, p_{L}, p_{H}\right)$, where $\beta$ and $\varepsilon$ correspond to the unique autocracy's parameters, and $p_{L}$ and $p_{H}$ to the boundaries of the voting action set. An outcome is then $O \equiv(\Psi, \tau)$, the voting action for households and tax action for autocracies.

\subsection{Characterization of Equilibrium Outcomes.}

As before, I start with the static equilibria and then use them to characterize the trigger equilibria that specify "revert to static" in case of deviation. The strategies that support these equilibria are analogous to the ones of proposition 1 and 2. In static equilibria, strategies do not depend on the history and always pick the actions $\Psi^{s}$ and $\tau^{s}$. In revert-to-static equilibria, strategies specify the actions $\Psi^{r}$ and $\tau^{r}$ if there was no deviations up to that moment, and $\Psi^{s}$ and $\tau^{s}$ if, otherwise, previously observed values for $\Psi$ and $\tau$ and do not correspond to $\Psi^{r}$ and $\tau^{r}$.

Proposition 6 (Static equilibrium) $O^{s} \equiv\left(\Psi^{s}, \tau^{s}\right)$ is given by 


$$
\begin{aligned}
& \Psi^{s} \in\left[p_{L}, p_{H}\right] \\
& \tau^{s}=1-\left[\beta \Psi^{s} A^{1-\varepsilon} \beta_{o}^{1-\varepsilon}\right]^{1 / \varepsilon}
\end{aligned}
$$

Proof. Since households are indifferent beween reelecting the incumbent autocracy or not, $\Psi^{s}$ is just constrained to be in the feasible set. Autocracies "static respond" to the probability of election $\Psi^{s}$ and to the households' savings rate $1-\Theta=\beta_{o}$

Proposition 7 ( $A$ set of equilibrium outcomes) The revert-to-static outcomes, $O^{r} \equiv\left(\Psi^{r}, \tau^{r}\right)$ satisfy

$$
\Psi^{r} \in\left[p_{L}, p_{H}\right]
$$

$\left(\tau^{r}\right)^{1-\varepsilon} /\left\{1-\beta \Psi^{r}\left[A \beta_{o}\left(1-\tau^{r}\right)\right]^{1-\varepsilon}\right\} \geq\left[1-\left(\beta \Psi^{s}\right)^{1 / \varepsilon}\left(A \beta_{o}\right)^{(1-\varepsilon) / \varepsilon}\right]^{-\varepsilon}$ (where $\Psi^{s}$ is a static equilibrium action)

Proof. Again households can freely choose $\Psi^{r}$. Autocracies actions are subject to a compatibility constraint that is obtained by making $U\left(\Psi^{r}, \tau^{r}\right) \geq U\left(\Psi^{s}, \tau^{s}\right)$. To prove that $O^{r}$ is an equilibrium outcome one can use exactly the same arguments that were used in proposition 2

Notice that the set of equilibria of proposition 7 includes the static equilibria of proposition 6 as special cases, by making $\Psi^{s}=\Psi^{r}$. Two benchmark cases in which this occurs are the examples 3 and 4.

\subsection{Examples.}

Example 3 (The "Unhappy Voter" Equilibrium) Consider the equilibrium in which, independently of the history, voters choose to reelect the incumbent autocracy with the lowest possible probability. In the notation of proposition 6 this means $\Psi^{s}=\Psi^{r}=p_{L}$. The equilibrium outcome is then

$$
\begin{aligned}
\Psi^{u} & =p_{L} \\
\tau^{u} & =1-\left[\beta p_{L} A^{1-\varepsilon} \beta_{o}^{1-\varepsilon}\right]^{1 / \varepsilon}
\end{aligned}
$$


Example 4 (The "Happy Voter" Equilibrium) Consider now the case when voters, independently of the history, reelect incumbents with the highest probability $\Psi^{s}=\Psi^{r}=p_{H}$. The equilibrium outcome is

$$
\begin{aligned}
\Psi^{h} & =p_{H} \\
\tau^{h} & =1-\left[\beta p_{H} A^{1-\varepsilon} \beta_{o}^{1-\varepsilon}\right]^{1 / \varepsilon}
\end{aligned}
$$

Some of the equilibria of proposition 7 , in contrast, feature the use of voting to control politicians actions. In particular, I focus on the best equilibrium for voters, the case in which voters' strategies result in the lowest possible tax rates. I label it "The Wise Voter Equilibrium", without meaning, however, that in all the other equilibria voters are not (fully rationally) maximizing their payoffs.

Example 3 (The "Wise Voter" Equilibrium)

$$
\Psi^{h}=p_{H}
$$

$\tau^{w}$ given implicitly by

$$
\left(\tau^{w}\right)^{1-\varepsilon} /\left\{1-\beta p_{H}\left[A \beta_{o}\left(1-\tau^{w}\right)\right]^{1-\varepsilon}\right\}=\left\{1-\left(\beta p_{L}\right)^{1 / \varepsilon}\left(A \beta_{o}\right)^{(1-\varepsilon) / \varepsilon}\right\}^{-\varepsilon}
$$

Proposition 8 (Best equilibrium for voters) The revert-to-static equilibrium that provide households with the highest utility correspond to the case $\Psi^{s}=p_{L}$ and $\left(\Psi^{r}, \tau^{r}\right)=\left(\Psi^{w}, \tau^{w}\right)$, where $\left(\Psi^{w}, \tau^{w}\right)$ is the "wise voter" equilibrium outcome.

Proof. The best equilibrium for voters happens when $\tau^{r}$ is the lowest possible. Let us define a function $G\left(\tau^{r}\right)=\left(\tau^{r}\right)^{1-\varepsilon} /\{1-$ $\left.\beta \Psi^{r}\left[A \beta_{o}\left(1-\tau^{r}\right)\right]^{1-\varepsilon}\right\}$, the LHS of the inequality in proposition 7 . It can be shown that $G\left(\tau^{r}\right)$ is concave, and, therefore, that inequality provide us with a lower and an upper bound for $\tau^{r}$. We are interested in the equilibrium in which the lower bound is binding, and $\partial G\left(\tau^{r}\right) / \partial \tau^{r}>0$. With this in mind, by using the implicit function theorem one can show that this lower bound decreases when $\Psi^{r}$ increases or when $\Psi^{s}$ decreases. Hence, to minimize it, $\Psi^{r}$ and $\Psi^{s}$ are chosen equal to the corners of the action space, $p_{H}$ and $p_{L}$. The 
lowest $\tau^{r}$ is equal to this bound

In figure 3 we can see better the actions and payoffs in the various equilibria. Higher probabilities of reelection shift autocracies payoffs up and to the left: the utility levels are higher and the optimal $\tau$ is lower (to see why this is so look at the proof of proposition 1 , in the appendix). In static equilibria, as examples 3 and $4, \tau$ is freely chosen for a given $p$, and hence corresponds to the optimal $\tau$ for a payoff curve. In trigger equilibria $\tau$ is constrained to some certain range, obtained from comparisons of different curves. In particular, in example $5, \tau$ is such that the payoff under $p_{H}$ is equal (or slightly superior) to the unconstrained payoffs under $p_{L}$.

More importantly, we should evaluate equilibria welfare. Payoffs for the households are independent of the probabilities of reelection, and always increase when $\tau$ decrease. More formally, I state

Proposition 9 (Welfare in the equilibria of examples 3, 4 and 5)

$$
\begin{aligned}
& U_{o}^{w} \geq U_{o}^{h} \geq U_{o}^{u}, U^{h} \geq U^{u}=U^{w} \\
& \partial U_{o}^{w} / \partial p_{H} \geq 0, \partial U_{o}^{w} / \partial p_{L} \leq 0, \partial U^{w} / \partial p_{H} \leq 0, \partial U^{w} / \partial p_{L} \geq 0
\end{aligned}
$$

Proof. Straightforward from the expressions previously obtained

The analysis of the wise voter equilibrium suggests that the electorate control over politicians is limited by the size of the voting space. The further apart $p_{H}$ and $p_{L}$ are, the tighter might political discipline be. Recalling that this voters-politician relation is a case of a principal-agent problem, we can think of the size of the voting set as a measure of "agency costs":

Definition 2 (Agency Costs) An economy $E \equiv\left(A, \beta_{o}, \beta, \varepsilon, p_{L}, p_{H}\right)$ has higher agency costs than an economy $E^{\prime} \equiv\left(A, \beta_{o}, \beta, \varepsilon, p_{L}^{\prime}, p_{H}^{\prime}\right)$ if $p_{H}^{\prime}>p_{H}>p_{L}>p_{L}^{\prime}$.

Notice that lower agency costs do not necessarily imply higher welfare for voters. There are always many possible equilibria in this economy, with many diverse outcomes. Rather, it implies that the 


\section{Fabio Kanczuk}

wise voter equilibrium, according to proposition 9 , yields higher welfare.

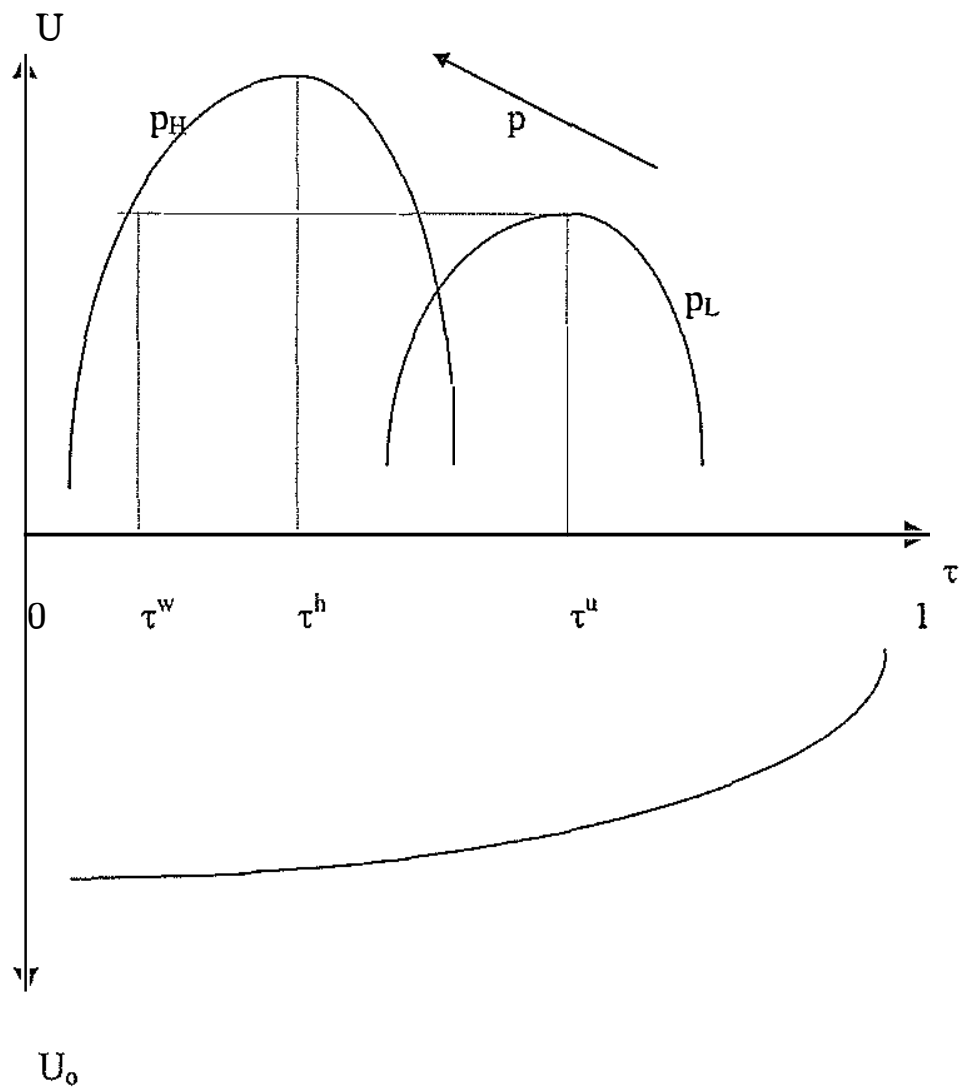

Figure 3: Electoral Control Equilibria 


\section{Conclusion.}

Why does Zaire grow so much less than the United States?

I addressed the primary puzzle of Economic Development, the non-convergence in countries' wealth using "politics" as the relevant explanatory channel. For this, I extended a simple growth model replacing the representative agent with households and politicians. The latter were motivated as kleptocrats, whose appetite to appropriate resources is constrained by an electoral process. This, I argue, is a good assumption for both the cases of the United States and Zaire. The difference, if we assume that preferences and technology are the same, resides on the electoral control.

I model electoral control by choosing size of the voting space. That is, when households can, in fact, choose whether to reelect incumbent, they are able to induce the politician to distort less the economy, increasing the growth rate and welfare.

When electoral control is weak, the economy displays oscillatory movements at medium frequencies, which I call "distortionliberalization cycles", due to different behavior of the incumbent autocracies, which deliberately decide between regimes of high or moderate taxation. The stochastic behavior of this distortion can be interpreted as "political risk", defined in very general terms, along the lines of Rothchild and Stiglitz (1970).

In the analysis, I called "government" the whole group that benefits from a monopoly of coercive power. In a modern democracy, it potentially includes all the branches, executive, legislative and judiciary, as well as favored state-owned enterprises workers, when they receive wages (well) above their marginal product. One interesting direction for future research is to study the interactions within the government, or the relations between members of the government, and see how these affect the growth performance of an economy. 
Another direction would be to use the model developed to perform some empirical experiments. That maybe would require some modifications in the modeling, as, for example, substituting the AK framework for better empirically supported functional forms, and solving numerically for equilibrium. Potentially, we could ask quantitative questions as "How rich would Zaire be if it had the United States' political environment?"

Submitted in December 2000. Revised in June 2001.

\section{References}

Alesina, A., S. Ozler, N. Roubini, \& P. Swagel 1996. "Political Instability and Economic Growth". Journal of Economic Growth 1:189-211.

Alesina, A. \& D. Rodrik 1994. "Distributive Politics and Economic Growth". Quarterly Journal of Economics 109:465-490.

Azariadis, C. \& A. Drazen 1990. "Threshold Externalities in Economic Development". Quarterly Journal of Economics 105:501526.

Barro, R. \& X. Sala-I-Martin 1995. Economic Growth. McGrawHill.

Benhabib, J. \& A. Rustichini 1994. "A note on a new class of solutions to dynamic programming problems arising in economic growth". Journal of Economic Dynamics and Control 18:807813.

Benhabib, J. \& A. Rustichini 1996. "Social Conflict and Growth". Journal of Economic Growth 1:125-142.

Chari, V. V. \& P. Kehoe 1990. "Sustainable Plans". Journal of Political Economy 98:783-801. 
Cukierman, A., S. Edwards, \& G. Tabellini 1992. "Seignorage and Political Instability". American Economic Review 82:537-555.

Ferejohn, J. 1986. "Incumbent Performance and Electoral Control". Public Choice 50:5-26.

Fudenberg, D. \& D. Levine 1994. "Efficiency and Observability with Long-Run and Short-Run Players". Journal of Economic Theory 62: 103-136.

Fudenberg, D. \& J. Tirole 1993. Game Theory. MIT Press.

Grossman, H.I. 1991. "A General Equilibrium Model of Insurrections". American Economic Review 81:912-921.

Hall, R. E. 1988. "Intertemporal substitution in Consumption". Journal of Political Economy 96:339-357.

Hirshleifer, J. 1989. "Conflict and rent-seeking sucess functions: Ratio vs. difference models of relative sucess". Public Choice 63:101-112.

Krussel, P., V. Quadrini, \& J. V. Rios-Rull 1997. "PoliticoEconomic Equilibrium and Economic Growth". Journal of Economic Dynamics and Control 21:243-272.

Levine, R. \& D. Renelt 1992. "A Sensitivity Analysis of CrossCountry Growth Regressions". American Economic Review 82:942-963.

Lucas, R. E. Jr. 1988. "On the Mechanics of Economic Development". Journal of Monetary Economics 22:3-42.

Mauro, P. 1995. "Corruption and Growth ". Quarterly Journal of Economics 110(3):681-712.

Meltzer, A. H. \& S. F. Richard 1981. "A Rational Theory of the Size of Government". Journal of Political Economy 89.

Mills, E. S. 1986. "Positive Theories of Government". Chapter 9 in The Burden of Government, Stanford: Hoover. 
Persson, T. \& G. Tabellini 1994. "Is inequality Harmful for Growth?" American Economic Review 84:600-621.

Rebelo, S. 1991. "Long-Run Policy Analysis and Long-Run Growth". Journal of Political Economy 99:500-521.

Rothschild, M. \& J. E. Stiglitz 1970. "Increasing Risk I: A Definition". Journal of Economic Theory 2:225-243.

Rothchild, M. \& J. E. Stiglitz 1971. "Increasing Risk II: Its Economic Consequences". Journal of Economic Theory 3:66-84.

Tullock, G. 1987. Autocracy. Kluwer Academic Publishers.

\section{Appendix.}

Proposition 1: The equilibrium outcome of static strategies, $O^{r} \equiv$ $\left(\Theta^{s}, \tau_{1}^{s}, \ldots, \tau_{N}^{s}\right)$, is the solution to the system of equations:

$$
\begin{aligned}
& \Theta^{s}=1-\left[\beta_{o} A^{1-\varepsilon_{o}} \sum_{j=1}^{N} p_{j}\left(1-\tau_{j}^{s}\right)^{1-\varepsilon_{o}}\right]^{1 / \varepsilon_{o}} \\
& \tau_{j}^{s}=1-\left[\beta_{j} p_{j} A^{1-\varepsilon_{j}}\left(1-\Theta^{s}\right)^{1-\varepsilon_{j}}\right]^{1 / \varepsilon_{j}}, j \in\{1, \ldots, N\}
\end{aligned}
$$

Proof. When strategies are static we can write the problem of an household $i$ as

$\operatorname{Max}_{\theta_{t}(i)} E \sum_{t=0}^{\infty} \beta_{o}^{t} u_{o}\left(c_{t}(i)\right)$

where

$u\left(c_{t}(i)\right)=\left[c_{t}(i)\right]^{1-\varepsilon_{o}} /\left(1-\varepsilon_{o}\right)$ if $\varepsilon_{o} \in(0,1)$

$u\left(c_{t}(i)\right)=\ln \left(c_{t}(i)\right)$ if $\varepsilon_{o}=1$

$c_{t}(i)=\theta_{t}(i) y_{t}(i)$

Subject to

$y_{t+1}(i)=A y_{t}(i)\left[1-\theta_{t}(i)\right]\left[1-\tau_{j, t+1}\right]$

where $\tau_{j, t+1}=\tau_{j}^{s}$ with probability $p_{j}, j \in\{1, \ldots, N\}$

and $y_{o}(i)$ is given. 
This problem can be transformed in the functional equation $V_{o}(y)=\operatorname{Max}_{\Theta}\left\{u(\Theta y)+E \beta_{o} V_{o}\left(y^{\prime}\right)\right\}$

such that

$y^{\prime}=A y[1-\Theta]\left[1-\tau_{j}^{s}\right]$ with probability $p_{j}$

For the case $\varepsilon_{o} \in(0,1)$, I proceed by "guessing" the functional form of $V_{o}(y)$ as

$$
V_{o}(y)=F_{o} y^{1-\varepsilon_{o}}
$$

(see Benhabib and Rustichini (1994))

(An solution for the case $\varepsilon_{o}=1$, omitted here, can be similarly obtained through by guessing $\left.V_{o}(y)=E_{o}+F_{o} \ln (y)\right)$

This leads to

$$
\begin{aligned}
& \Theta^{s}=\operatorname{ArgMax}_{\Theta}\left\{(\Theta y)^{1-\varepsilon_{o}}+\beta_{o} \sum_{j} p_{j} F_{o}\left[A(1-\Theta)\left(1-\tau_{j}^{s}\right)\right]^{1-\varepsilon_{o}}\right\} \\
& \Theta^{s}=\operatorname{ArgMax}_{\Theta}\left\{\Theta^{1-\varepsilon_{o}}+(1-\Theta)^{1-\varepsilon_{o}} \beta_{o} A^{1-\varepsilon_{o}} F_{o} \sum_{j} p_{j}(1-\right. \\
& \left.\left.\tau_{j}^{s}\right)^{1-\varepsilon_{o}}\right\} \\
& \Theta^{s}=1 /\left(1+G_{o}\right),
\end{aligned}
$$

where $G_{o}=\left\{\beta_{o} A^{1-\varepsilon_{o}} F_{o} \sum_{j} p_{j}\left(1-\tau_{j}^{s}\right)^{1-\varepsilon_{o}}\right\}^{1 / \varepsilon_{o}}$

Plugging the expression for $\Theta^{s}$ back into the functional equation, we obtain

$$
\begin{aligned}
& F_{o} y^{1-\varepsilon_{o}}=y^{1-\varepsilon_{\circ}} /\left(1+G_{o}\right)^{1-\varepsilon_{o}}+y^{1-\varepsilon_{o}}\left[G_{o}^{1-\varepsilon_{o}} \beta_{o} A^{1-\varepsilon_{o}} F_{o} \sum_{j} p_{j}(1-\right. \\
& \left.\left.\tau_{j}^{s}\right)^{1-\varepsilon_{o}}\right] /\left(1+G_{o}\right)^{1-\varepsilon_{o}}
\end{aligned}
$$

The last two expressions form a system for $F_{o}$ and $G_{o}$. Solving for $F_{o}$ we obtain

$$
F_{o}=\left\{1-\left[\beta_{o} A^{1-\varepsilon_{o}} \sum_{j} p_{j}\left(1-\tau_{j}^{s}\right)^{1-\varepsilon_{o}}\right]^{1 / \varepsilon_{o}}\right\}^{-\varepsilon_{o}}
$$

From the expression for $\Theta^{s}$ and the relation between $F_{o}$ and $G_{o}$ we now obtain

$$
\Theta^{s}=1 /\left(F_{o}\right)^{1 / \varepsilon_{0}}
$$

And from the expression for $F_{o}$ 
Fabio Kanczuk

$$
\Theta^{s}=1-\left[\beta_{o} A^{1-\varepsilon_{o}} \sum_{j} p_{j}\left(1-\tau_{j}^{s}\right)^{1-\varepsilon_{o}}\right]^{1 / \varepsilon_{\circ}}
$$

Analogously, an autocracy $j$ solves

$$
\operatorname{Max}_{r_{j, t}} E \sum_{t=0}^{\infty} \beta_{j}^{t} u_{j}\left(g_{t}\right)=\sum_{t=0}^{\infty}\left(\beta_{j} p_{j}\right)^{t} u_{j}\left(g_{t}\right)
$$

where

$u_{j}\left(g_{t}\right)=\left[g_{t}\right]^{1-\varepsilon_{j}} /\left(1-\varepsilon_{j}\right)$ if $\varepsilon_{j} \in(0,1)$

$u_{j}\left(g_{t}\right)=\ln \left(g_{t}\right)$ if $\varepsilon_{j}=1$

$g_{t}=\tau_{j, t} A k_{t}$

Subject to the budget constraint

$k_{t+1}=A k_{t}\left[1-\tau_{j, t}\right]\left[1-\Theta_{t}^{s}\right]$

This problem can be transformed in the functional equation

$V_{j}^{r}(k)=M a x_{\tau_{j}}\left\{u\left(\tau_{j} A k\right)+E \beta_{j} V_{j}\left(k^{\prime}\right)\right\}$

such that

$k^{\prime}=A k\left[1-\Theta^{s}\right]\left[1-\tau_{j}\right]$

For the case $\varepsilon_{j} \in(0,1)$, I proceed by "guessing" the functional form of $V_{j}(k)$ as

$$
V_{j}(k)=F_{j} k^{1-\varepsilon_{j}}
$$

(An solution for the case $\varepsilon_{j}=1$, omitted here, can be similarly obtained through by guessing $\left.V_{j}(y)=E_{j}+F_{j} \ln (k)\right)$

Using the same procedure, we obtain

$$
F_{j}=\left\{1-\left[\beta_{j} p_{j} A^{1-\varepsilon_{j}}\left(1-\Theta^{s}\right)^{1-\varepsilon_{j}}\right]^{1 / \varepsilon_{j}}\right\}^{-\varepsilon_{j}}
$$

and

$$
\tau_{j}^{s}=1-\left[\beta_{j} p_{j} A^{1-\varepsilon_{j}}\left(1-\Theta^{s}\right)^{1-\varepsilon_{j}}\right]^{1 / \varepsilon_{j}}
$$

Proposition 5: Economies with riskier political systems have lower private investment rates and, consequently, slower growth. Households are worse off in economies with riskier political systems 
Proof. To prove the first part of proposition 5 I first state the lemma 1 (Rothschild and Stiglitz, 1971):

Lemma 1. Consider two random variables $\tilde{\tau}^{1}$ and $\tilde{\tau}^{2}$, with cumulative distributions $T_{1}$ and $T_{2}$, and $\tilde{\tau}^{2}$ riskier than $\tilde{\tau}^{1}$. Let $\Theta_{i}^{*}$ be the solution to:

$$
V\left(\tilde{\tau}^{i}\right)=\operatorname{Max}_{\Theta^{i}} U\left(\Theta, \tilde{\tau}^{i}\right)=\int v(\Theta, \tau) d T_{i}(\tau) \text {, for } i=1,2
$$

Suppose that $\Theta_{i}^{*}$ is the unique turning point of $U\left(\Theta, \tilde{\tau}^{i}\right)$. Then if $\partial v / \partial \Theta$ is a concave (convex) function of $\tau, \Theta_{1}^{*}$ is greater than (less than) $\Theta_{2}^{*}$. If $V_{i}$ is concave in $\tilde{\tau}$, the concavity being strict somewhere then $V_{1}>V_{2}$.

Now, from the maximization of proposition 1 , I rewrite

$$
\underset{\left.\left.\tau_{j}^{s}\right)^{1-\varepsilon_{o}}\right\}}{\Theta^{s}}=\operatorname{ArgMax}\left\{\Theta^{1-\varepsilon_{o}}+(1-\Theta)^{1-\varepsilon_{o}} \beta_{o} A^{1-\varepsilon_{o}} F_{o} \sum_{j} p_{j}(1-\right.
$$

Comparing the two expressions, we can define

$v=\Theta^{1-\varepsilon_{o}}+(1-\Theta)^{1-\varepsilon_{o}} \beta_{o} A^{1-\varepsilon_{o}} F_{o}(1-\tau)^{1-\varepsilon_{o}}$, and recall that $\tilde{\tau}$ is the political system.

Since $\partial v / \partial \Theta$ is a concave function of $\tau$, it is straightforward to conclude that an increase in political risk implies higher $\Theta$, and, hence, lower private investment rates.

For the second part of the proposition I use the coefficient $F_{o}$ obtained in the proof of proposition 1:

$$
F_{o}=\left\{1-\left[\beta_{o} A^{1-\varepsilon_{o}} \sum_{j} p_{j}\left(1-\tau_{j}^{s}\right)^{1-\varepsilon_{o}}\right]^{1 / \varepsilon_{o}}\right\}^{-\varepsilon_{o}}
$$

Now I redefine

$$
\begin{gathered}
V(\tilde{\tau})=(1-\tilde{\tau})^{1-\varepsilon_{0}} \text { and point out that } F_{o} \text { increases with } \\
\int V(\tau) d T_{i}(\tau)
\end{gathered}
$$

Since $V$ is strictly concave in $\tilde{\tau}, V_{1}>V_{2}$ and therefore, households are better-off in economies with less risky political systems. 